\title{
Bacterial Load in Daily Urine Samples of Patients Infected with Mycoplasma genitalium, Mutation Analysis, and Response to Treatment
}

\author{
M. Gossé, ${ }^{1}$ S. A. Nordbø, ${ }^{2,3}$ and B. Pukstad ${ }^{1,4}$ \\ ${ }^{1}$ Department of Cancer Research and Molecular Medicine, Norwegian University of Science and Technology, Trondheim, Norway \\ ${ }^{2}$ Department of Laboratory Medicine, Children's and Women's Health, Norwegian University of Science and Technology, \\ Trondheim, Norway \\ ${ }^{3}$ Department of Medical Microbiology, St. Olavs Hospital, Trondheim University Hospital, Trondheim, Norway \\ ${ }^{4}$ Department of Dermatology, St. Olavs Hospital, Trondheim University Hospital, Trondheim, Norway
}

Correspondence should be addressed to M. Gossé; mariannegosse@gmail.com

Received 20 August 2016; Accepted 27 September 2016

Academic Editor: Bryan Larsen

Copyright (C) 2016 M. Gossé et al. This is an open access article distributed under the Creative Commons Attribution License, which permits unrestricted use, distribution, and reproduction in any medium, provided the original work is properly cited.

\begin{abstract}
Objective. Increasing macrolide resistant strains of Mycoplasma genitalium is a challenge, and to differentiate between treatment failure and reinfection a timely test of cure (TOC) is warranted. The aim of this study was to evaluate the best time for TOC after five days' treatment of Mycoplasma genitalium infection with azithromycin. Methods. Nineteen patients with positive PCR for Mycoplasma genitalium in urine provided urine samples daily for 2 weeks and on days 21, 28, and 35. Samples were tested by a commercial qPCR and by sequencing of the $23 \mathrm{~S}$ rRNA gene. Results. Eight patients with a wild type of Mycoplasma genitalium responded successfully within four days after treatment initiation. Eleven patients had a mutation in the 23S rRNA gene. These samples exhibited high variations in bacterial load, and some patients tested negative at several time points during the observation period. Conclusions. Day-to-day fluctuations in the mutation samples allow for false negative TOC during the first 5 weeks after start of treatment. Due to increasing macrolide resistance of Mycoplasma genitalium, pretreatment mutation analysis is recommended. When a wild type is verified, TOC performed one week after initiation of treatment is suggested.
\end{abstract}

\section{Introduction}

Mycoplasma genitalium is a sexually transmitted bacterium able to cause acute and chronic nongonococcal urethritis (NGU) in men $[1,2]$ and urethritis, cervicitis, and pelvic inflammatory disease (PID) in women [1-3], although in many cases the infection is asymptomatic $[4,5]$. The recommended treatment for NGU when caused by Chlamydia trachomatis, or when bacterial species is unknown, is a 7-day course of doxycycline (100 mg twice daily) [6]. Studies show that doxycycline is less effective in treating $M$. genitalium, with varying cure rates across studies and a pooled cure rate of $42 \%$ [7]. $1 \mathrm{~g}$ of azithromycin given as a single dose has shown higher cure rates $[8,9]$, but an extended course of $1,5 \mathrm{~g}$ given as $500 \mathrm{mg}$ on day 1 and $250 \mathrm{mg}$ on days $2-5$ is recommended in Scandinavia to avoid induced macrolide resistance $[10,11]$.
Unemo et al. showed that this treatment regimen is also effective in eradicating C. trachomatis. In recent years, several studies have shown an increase in treatment failure following the use of azithromycin in M. genitalium infections [12-14]. Jensen et al. found mutations in region $\mathrm{V}$ of the 23S rRNA gene in positions 2058 and 2059 (Escherichia coli numbering) accounting for some of the macrolide failures seen [15]. High bacterial load may also be associated with treatment failure $[16,17]$. In cases of treatment failure moxifloxacin, a fluoroquinolone, is recommended as a second line treatment [7].

The recommended time for test of cure (TOC) in Norway is 4-5 weeks after treatment initiation (Norwegian Institute of Public Health). Most countries have a similar practice [6]. To our knowledge, there are very few published studies evaluating the optimal time for TOC for M. genitalium. In 
a study by Bissessor et al., samples taken at day 14 yielded the same result as samples taken at day 28 after treatment, and the authors propose TOC to be conducted after 14 days [14]. Reducing TOC to 14 days would reduce false positive results due to reinfection and enable initiation of second line treatment at an earlier time, thus reducing potential transmission of resistant strains. A recent study by Falk et al. states, however, that a TOC should not be conducted earlier than 3-4 weeks, due to induced resistance in a limited number of samples [18].

The aim of this study was to evaluate the best time for test of cure after treating $M$. genitalium infection with a five-day course of azithromycin. Response to treatment was monitored over a period of 5 weeks in nineteen patients with positive PCR for $M$. genitalium in urine. The samples were analyzed and compared with mutation analyses and outcome of treatment. Both patients with symptoms and without symptoms were included.

\section{Materials and Methods}

2.1. Patient Recruitment and Sample Collection. Recruitment took place at the Outpatient Clinic of Venereal Disease, St. Olavs Hospital, Norway, and at a sexual health clinic for students. Untreated patients testing positive for M. genitalium were asked to participate in the study. Those testing positive for Chlamydia trachomatis or Neisseria gonorrhoeae were not included. Upon recruitment, participants signed a consent form and provided a pretreatment urine sample. To avoid spread of infection in case of treatment failure and reinfection during the study period, the participants were instructed to use a condom until test of cure results were available. Twenty patients participated in the study, six males and fourteen females, and the median age was 22 years (range 18-33 years). Four patients presented with self-reported symptoms of discharge, in one case bloody, pruritus, and dysuria, whereas the others were asymptomatic throughout the study period. All patients received a five-day azithromycin $1,5 \mathrm{~g}$ extended course: $500 \mathrm{mg}$ on day 0 and $250 \mathrm{mg}$ on days $1-4$ (project day numbering). Patients were provided with all necessary equipment and an instruction manual. On day 1 through day 14, all patients took a first void urine (FVU) sample daily and transferred it into $9 \mathrm{~mL}$ plastic tubes. The patients were instructed to provide the first urine of the day or at least wait for one hour after micturition before sampling, to allow potential bacteria to accumulate in the urethra. The tubes were then stored at $-20^{\circ} \mathrm{C}$ in the participants' freezers. The same procedure was conducted on days 21 (three weeks), 28 (four weeks), and 35 (five weeks). At the end of the sampling period, the seventeen urine samples were transferred to the laboratory and stored at $-80^{\circ} \mathrm{C}$. The urine samples from all patients were then DNA extracted on the same day, in a total of 15 batches, and the eluates were stored at $-80^{\circ} \mathrm{C}$ until analyzed. Collectively this resulted in the possibility of two freeze-thaw cycles for the urine samples and one for the eluate. Patient recruitment and data collection commenced in October 2014, and the last set of samples were collected in June 2015.
One patient (patient 5) decided to withdraw from the project, and patient 21 was therefore recruited. Another patient (patient 11) was later excluded because it turned out she had been included based on a positive vaginal swab sample and not urine. She did have six positive urine samples throughout the study period, but as the first couple of samples were negative in urine she did not fulfil the inclusion criteria. The total number of participants in the project was therefore nineteen.

2.2. DNA Extraction. To obtain maximal sensitivity, DNA was extracted from $1 \mathrm{~mL}$ urine using the NucliSens EasyMag system (bioMérieux SA, Marcy l'Etoile, France), yielding $55 \mu \mathrm{L}$ of eluate. The eluates were stored at $-80^{\circ} \mathrm{C}$ until further processing.

2.3. Quantitative PCR. Quantitative PCR ( $\mathrm{qPCR}$ ) was conducted using a CFX96 Real-Time PCR instrument (Bio-Rad Laboratories Inc., Hercules, CA, USA) and the FTD Urethritis basic detection kit (Fast-Track Diagnostics Ltd., Sliema, Malta), for the simultaneous detection of Mycoplasma genitalium, Chlamydia trachomatis, and Neisseria gonorrhoeae. All qPCR runs contained an internal positive control to ensure that no inhibitors were present in the DNA extracts. Quantitation of bacteria per $\mathrm{mL}$ was performed according to the manufacturers' instructions. A validated equation was used to calculate copy numbers per $\mathrm{mL}$. All samples belonging to the same patient were tested in the same run.

2.4. Sequencing. A minimum of one sample from each patient was sequenced using Beckman Coulter CEQ8800 Genetic Analysis System (Beckman Coulter Inc., Brea, CA, USA). In an attempt to secure a solid sequencing result, the samples with the lowest cycle threshold values were chosen for sequencing. We used Rapid Cleanup Enzyme Set (New England BioLabs Inc., Ipswich, England) for PCR product cleanup and Bio-Analyzer (Agilent Technologies Inc., Santa Clara, CA, USA) for DNA concentration measuring. GenomeLab ${ }^{\text {TM }}$ DTCS Quick Start Kit (Beckman Coulter Inc.) was used for dye terminator cycle sequencing of a $241 \mathrm{bp}$ amplicon from the 23S rRNA gene (sense primer "5-GGTTAAAGAAGGAGGTTAGCAATTT-3" and anti-sense primer "5-AGCTACAGTAAAGCTTCACTGGG3”) (TIB Molbiol, Berlin, Germany).

2.5. Ethics and Biobanking. The study was approved by the Regional Ethics Committee (REK Midt-Norge). All urine samples and DNA eluates were registered at the Regional Biobank of Central Norway and stored at $-80^{\circ} \mathrm{C}$.

\section{Results}

Ten of the nineteen patients tested positive for M. genitalium and nine tested negative at the end of the followup period (Table 1). New treatment was considered among those still testing positive at this time. Eight patients received moxifloxacin immediately after the positive test result from the TOC was available. Two patients ( 3 and 6 ) received a 
TABLE 1: Patient number, symptoms, bacterial type, and bacterial load at baseline and on day 4 after treatment with azithromycin $1,5 \mathrm{~g}$. Patients 5 and 11 were excluded from the study. Patient 3 had a negative pretreatment sample but had a titer of $2,36 \times 10^{2}$ copies $/ \mathrm{mL}$ on day 1. Patient 20 was unable to provide a pretreatment sample due to recent micturition and had a titer of $4,01 \times 10^{5}$ copies $/ \mathrm{mL}$ on day 1. Patients 13 and 15 had a negative test at day 35 but tested positive at their follow-up appointment a few days later.

\begin{tabular}{|c|c|c|c|c|}
\hline $\begin{array}{l}\text { Participant } \\
\text { number }\end{array}$ & Symptoms & $\begin{array}{c}\text { Bacterial } \\
\text { load at } \\
\text { baseline, } \\
\text { copies } / \mathrm{mL}\end{array}$ & $\begin{array}{c}\text { Bacterial } \\
\text { load at day } \\
4, \\
\text { copies } / \mathrm{mL}\end{array}$ & $\begin{array}{c}\text { Bacterial } \\
\text { load at day } \\
35, \\
\text { copies } / \mathrm{mL}\end{array}$ \\
\hline \multicolumn{5}{|l|}{ Wild type } \\
\hline 1 & - & $1,30 \times 10^{3}$ & - & - \\
\hline 2 & - & $1,86 \times 10^{4}$ & - & - \\
\hline 4 & - & $4,80 \times 10^{2}$ & - & - \\
\hline 7 & - & $4,96 \times 10^{1}$ & - & - \\
\hline 12 & - & $3,18 \times 10^{2}$ & - & - \\
\hline 14 & - & $5,97 \times 10^{3}$ & - & - \\
\hline 18 & - & $1,20 \times 10^{3}$ & - & - \\
\hline 19 & - & $6,97 \times 10^{2}$ & - & - \\
\hline \multicolumn{5}{|l|}{$\begin{array}{l}\text { A2058G } \\
\text { mutation }\end{array}$} \\
\hline 3 & - & - & $4,31 \times 10^{2}$ & $3,09 \times 10^{2}$ \\
\hline 9 & Symptomatic & $1,13 \times 10^{3}$ & $6,64 \times 10^{2}$ & $7,56 \times 10^{2}$ \\
\hline 17 & Symptomatic & $1,91 \times 10^{4}$ & $8,66 \times 10^{3}$ & $4,08 \times 10^{3}$ \\
\hline 21 & - & $1,40 \times 10^{5}$ & $7,28 \times 10^{5}$ & $2,56 \times 10^{3}$ \\
\hline \multicolumn{5}{|l|}{$\begin{array}{l}\text { A2059G } \\
\text { mutation }\end{array}$} \\
\hline 6 & - & $4,70 \times 10^{2}$ & $2,51 \times 10^{3}$ & $4,08 \times 10^{2}$ \\
\hline 8 & - & $3,47 \times 10^{2}$ & $9,92 \times 10^{3}$ & $2,37 \times 10^{2}$ \\
\hline 10 & - & $5,18 \times 10^{3}$ & $2,03 \times 10^{3}$ & $1,16 \times 10^{4}$ \\
\hline 13 & Symptomatic & $1,30 \times 10^{3}$ & $1,33 \times 10^{2}$ & - \\
\hline 15 & Symptomatic & $1,35 \times 10^{4}$ & $2,95 \times 10^{3}$ & - \\
\hline 16 & - & $3,79 \times 10^{3}$ & $3,76 \times 10^{3}$ & - \\
\hline 20 & - & $\begin{array}{c}\text { Not tested } \\
\text { on day } 0\end{array}$ & $1,92 \times 10^{5}$ & $7,06 \times 10^{2}$ \\
\hline
\end{tabular}

second course of azithromycin because reinfection could not be excluded. Patient 3 received moxifloxacin at the next appointment whereas patient 6 never showed up for a new appointment. Samples from one of the patients testing negative at TOC (patient 16) later revealed a mutant strain, whereas the rest of the patients testing negative at TOC were infected with a wild type. One patient (patient 20) was unable to provide a pretreatment sample because he had just emptied his bladder. Another patient (patient 3) had a negative pretreatment sample, though all the following posttreatment samples were positive, and the reason this patient was recruited was because he had a positive test ten days prior to start of sampling.

3.1. Mutation Analysis. Sequencing showed that eight patients had a wild type strain (Table 1). Patient 7 was negative on day 1 ; patients 12,14 , and 18 were negative on day

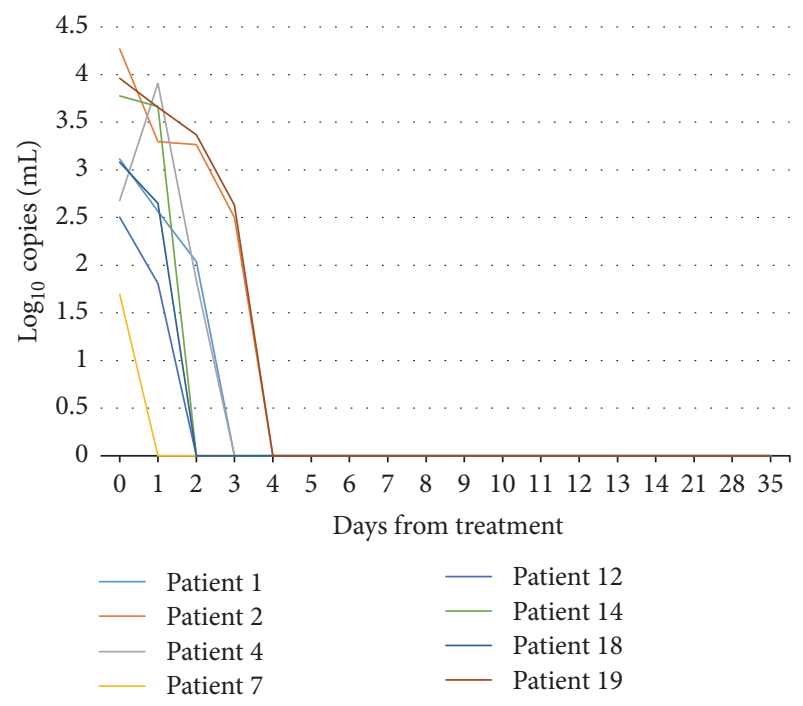

FIGURE 1: Bacterial load in participants infected with a wild type strain. Day 0 is pretreatment. All participants had negative urine samples from day 4 after treatment.

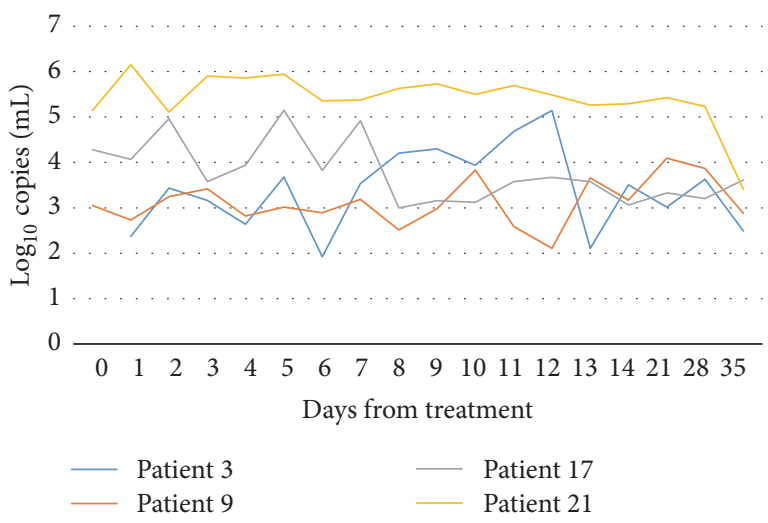

FIGURE 2: Bacterial load in participants infected with an A2058G mutation. All samples stayed positive throughout the whole test period.

2; patients 1 and 4 were negative on day 3; patients 2 and 19 were negative on day 4 (Figure 1). The eleven patients who experienced persistent infection had mutations in position 2058 or 2059. Four patients had an A2058G mutation and seven had an A2059G mutation. Among the patients with an A2059G mutation, one (patient 16) had positive samples the first fourteen days but had a negative PCR on days 21,28 , and 35 and at TOC.

3.2. Mutant Types Stayed Positive throughout Most of the Test Period. Patients 3, 9, 10, 15, 17, 20, and 21 had positive urine samples all throughout the test period, though the bacterial load fluctuations varied considerably from day to day (Figure 2). Patients 6, 8, 13, and 16 had some negative samples during the test period (Figure 3). These were all infected with an A2059G mutant type. Patient 6 had a 


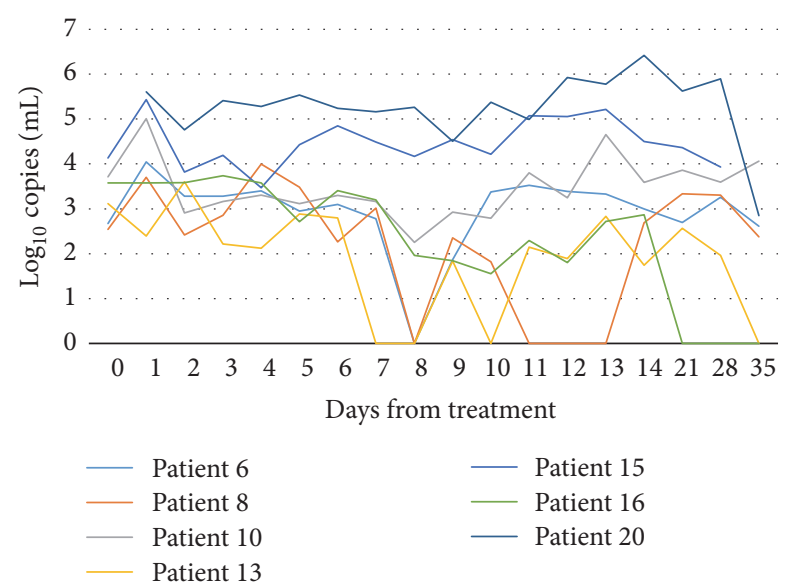

FIgURE 3: Bacterial load in participants infected with an A2059G mutation. Some patients had sporadic negative samples during the test period.

negative sample on day 8 , but from day 9 and forward all samples were positive. Patient 8 had negative samples on day 8 and days $10-13$, and patient 13 had negative samples on days 7 , 8,10 , and 35 . TOC taken on day 38 was positive, however, and the patient was treated with moxifloxacin with good effect. Patient 15 failed to deliver a test on day 35 , but the test of cure on day 37 was positive.

3.3. Symptoms. Four patients (patients $9,13,15$, and 17), three women and one man, presented with symptoms and were all infected with a mutant type. Patients 9 and 17 had an A2058G mutation and patients 13 and 15 had an A2059G mutation. Patients 15 and 17 experienced complete relief of symptoms after treatment; patient 9 experienced a lasting reduction but not complete relief; patient 13 experienced a reduction of symptoms but a flourishing of symptoms around day ten. All symptomatic patients received moxifloxacin after first TOC and delivered urine with negative PCR for M. genitalium at their next TOC.

\section{Discussion}

At present, the IUSTI European guideline recommends performing TOC after infection with M. genitalium 3-5 weeks after initiation of treatment [6]. Patients are instructed to use a condom while waiting for the results of their TOC, but adherence is variable. Thus, there is a risk of reinfection during this period and also spread of mutant strains if treatment has not been successful. Being able to conduct a TOC as early as possible is therefore warranted. In this study we followed nineteen patients with M. genitalium detected in urine closely for 5 weeks. They were all treated with the standard five-day regime of azithromycin. There was a clear pattern between wild type strains, where treatment was $100 \%$ effective during the 5 weeks of follow-up, and mutants, where the treatment had little or no effect. Patients infected with the wild type strain all delivered negative urine samples within four days of treatment.

4.1. Persistent Infection in Most Patients with Mutant Strains. Most patients with mutant strains stayed positive throughout the test period, but there were day-to-day fluctuations and even some negative samples. Even though patients were instructed to sample first void urine from the first toilet visit of the day or make sure not to micturate within at least one hour before sampling, the variations in bacterial load might be due to variations in time points of micturition and how long urine had stayed in the bladder before micturition. As far as we know, no one has conducted a study assessing the appropriate time for testing of M. genitalium after last micturition, and thus the impact of this is not known regarding bacterial load. The patients stored the samples in their own freezers and brought them to the clinic. Cyclic changes in freezer temperature and the possibility of thawing upon transport might have influenced the quantitative results to some degree.

The patients who had mostly positive but some negative samples during the test period were all infected with an A2059G mutant type. Several of the samples taken on adjacent days showed a bacterial count of $<100$ copies $/ \mathrm{mL}$, indicating that the samples might be false negative, due to a low bacterial load. Patient 16, who had positive samples the first fourteen days but had negative samples on days 21,28 , and 35 , had an A2059G mutation. The first week the average bacterial load was 3160 copies $/ \mathrm{mL}$ (range $514-5460$ copies $/ \mathrm{mL}$ ) and the second week the average load was 245 copies/mL (range 36-736 copies $/ \mathrm{mL}$ ). Even if there were day-to-day variations, there was a definite decline. However, it is not possible to conclude whether this was due to an effect of azithromycin or not. An additional sample taken on day 47 was also negative, indicating that the patient's immune system may have eradicated the infection on its own. No additional treatment was given to this patient, as the infection was cleared.

The target of the PCR used for the detection of M. genitalium is the mgpB gene. Sequence changes in this gene due to mutations and recombinations frequently occur, even within a time period as short as 10 days. Hence, mismatches between primers, probe, and the target may give rise to weak signals and even false negative results $[19,20]$. The rate of spontaneous clearance of $M$. genitalium is not well documented, although two cohort studies have examined aspects of its natural history. Oakeshott et al. reported that only $26 \%$ of M. genitalium positive women remained positive after 12-21 months [21], and Vandepitte et al. reported a 93\% spontaneous clearance rate after 12 months [22]. As pointed out by Smieszek et al., investigating the natural history of a sexually transmitted pathogen is difficult due to risk of reinfection during the follow-up [23].

All four symptomatic patients happened to be infected with a mutant type, and all four symptomatic patients reported some relief of symptoms after treatment. Azithromycin treatment has been reported to possess antiinflammatory properties, but its mechanism of action is still 
not fully understood [24]. In our study, the bacterial load did not differ substantially between symptomatic and nonsymptomatic patients.

4.2. Time for Test of Cure. In our limited material almost all patients had matching results on day 4 and day 35 . This suggests that a TOC could be performed within a week, giving the benefits of early testing. Though induced resistance did not occur in our material during the 5 weeks of followup, some researchers have reports of this $[15,18,25]$. Due to such induced resistance it is recommended to perform TOC no earlier than 3-4 weeks after initiation of treatment [26]. Can a negative TOC between week 3 and week 5 after treatment initiation then be trusted? In our study, a positive TOC taken $>4$ days after treatment indicated a mutant type, but a negative sample taken $>4$ days after treatment did not exclude the persistence of a mutant strain. These results indicate that a larger study is both important and necessary. One of our patients with a mutant strain (number 13) had a negative result on day 35 and a positive result on day 38 . With this in mind, a TOC should be done either very early, for example, one week after initiation of treatment, in order to detect possible mutations early, or after 5 weeks in order to reduce the chance of missing a possible induction of a wild type strain turning into a mutant strain.

In a few cases a negative test can be the result of a sample with a bacterial load below the detection limit of the PCR after macrolide treatment, which might be due to a low-grade infection or due to poor bacterial accumulation because of recent micturition. DNA extraction method, sensitivity of the PCR test, and attention to time of micturition are factors to consider when suspecting false negative results. A negative result can be misinterpreted as successful treatment even if the patient has not been cured.

It is important to note that, in this study, only urine samples were tested and we do not know if the results will apply to swab specimens as well. In the study of Falk et al., no differentiation between urine specimens and vaginal swabs was made [18], but Solberg shows in a recent study that vaginal swab samples are likely to contain a higher amount of bacterial DNA [27]. The superiority of vaginal swabs over urine samples is also shown by Wroblewski et al. [28] and Lillis et al. [29]. A study evaluating time to eradication of $M$. genitalium from vaginal swab specimens compared to urine specimens from women is therefore warranted.

Appropriate TOC after treatment of a mutant strain will depend on treatment given. TOC after quinolone or tetracycline treatment was not evaluated in this study, and further studies regarding this are needed.

4.3. High Prevalence of Resistant Types. Macrolide resistant types of M. genitalium were detected in 11 (58\%) of 19 patients in this study. This is in line with our findings in a larger study [30] in our region and has also been reported by others from Norway [31], England [13], Australia [14], Denmark [32, 33], and the Netherlands [34]. Hence, macrolide resistance is an increasing problem [31, 35-37]. With a high prevalence of resistant types, a mutation analysis should be performed on the first sample, both to avoid treatment failure with azithromycin and to avoid the use of macrolide antibiotics when it is not indicated.

\section{Conclusions}

In this study we found that a five-day azithromycin course is highly effective for eradication of the wild type strain of $M$. genitalium in urine within four days after onset of treatment. Our findings suggest that a TOC already one week after initiation of standard five-day treatment with azithromycin is recommended. However, our study was small, and no firm conclusions can be made. Hence, larger studies, including vaginal and possibly male urethral specimens, are warranted to confirm or discard our results. The prevalence of macrolide resistant strains seems to be increasing in Norway, and pretreatment mutation analysis of $M$. genitalium is recommended to guide treatment.

\section{Competing Interests}

The authors declare that there are no competing interests.

\section{Authors' Contributions}

Marianne Gossé, Svein Arne Nordbø, and Brita Pukstad made (i) substantial contributions to conception and design, or acquisition of data, or analysis and interpretation of data; (ii) substantial contributions to drafting the article or revising it critically for important intellectual content; (iii) substantial contributions to the final approval of the version to be published; and (iv) substantial contributions to the agreement to be accountable for all aspects of the work in ensuring that questions related to the accuracy or integrity of any part of the work are appropriately investigated and resolved.

\section{Acknowledgments}

The authors wish to thank Hilde Lysvand for excellent help with the laboratory training and analysis. They would also like to thank Silja Egilsdottir and Marte Mello Wibe for technical assistance with DNA extraction and qPCR and nurses and doctors at the Outpatient Clinic of Venereal Disease, St. Olavs Hospital, for help with inclusion and follow-up of patients. The Student Research Program at the Norwegian University of Technology and Science funded the study.

\section{References}

[1] C. Cazanave, L. E. Manhart, and C. Bébéar, "Mycoplasma genitalium, an emerging sexually transmitted pathogen," Medecine et Maladies Infectieuses, vol. 42, no. 9, pp. 381-392, 2012.

[2] D. Taylor-Robinson and J. S. Jensen, "Mycoplasma genitalium: from chrysalis to multicolored butterfly," Clinical Microbiology Reviews, vol. 24, no. 3, pp. 498-514, 2011.

[3] R. Lis, A. Rowhani-Rahbar, and L. E. Manhart, "Mycoplasma genitalium infection and female reproductive tract disease: a meta-analysis," Clinical Infectious Diseases, vol. 61, no. 3, pp. 418-426, 2015. 
[4] H. Moi, N. Reinton, and A. Moghaddam, "Mycoplasma genitalium is associated with symptomatic and asymptomatic nongonococcal urethritis in men," Sexually Transmitted Infections, vol. 85, no. 1, pp. 15-18, 2009.

[5] J. D. C. Ross, L. Brown, P. Saunders, and S. Alexander, "Mycoplasma genitalium in asymptomatic patients: Implications for screening," Sexually Transmitted Infections, vol. 85, no. 6, pp. 436-437, 2009.

[6] P. J. Horner, K. Blee, L. Falk, W. van der Meijden, and H. Moi, "2016 European guideline on the management of nongonococcal urethritis," International Journal of STD \& AIDS, vol. 27, no. 11, pp. 928-937, 2016.

[7] L. E. Manhart, J. M. Broad, and M. R. Golden, "Mycoplasma genitalium: should we treat and how?" Clinical Infectious Diseases, vol. 53, no. 3, pp. S129-S142, 2011.

[8] E. Björnelius, C. Anagrius, G. Bojs et al., "Antibiotic treatment of symptomatic Mycoplasma genitalium infection in Scandinavia: a controlled clinical trial," Sexually Transmitted Infections, vol. 84, no. 1, pp. 72-76, 2008.

[9] L. A. Mena, T. F. Mroczkowski, M. Nsuami, and D. H. Martin, "A randomized comparison of azithromycin and doxycycline for the treatment of Mycoplasma genitalium-positive urethritis in men," Clinical Infectious Diseases, vol. 48, no. 12, pp. 1649-1654, 2009.

[10] C. Anagrius, B. Loré, and J. S. Jensen, "Treatment of Mycoplasma genitalium. Observations from a Swedish STD clinic," PLoS ONE, vol. 8, no. 4, Article ID e61481, 2013.

[11] M. Unemo, K. M. A. Endre, and H. Moi, "Five-day azithromycin treatment regimen for mycoplasma genitalium infection also effectively eradicates chlamydia trachomatis," Acta DermatoVenereologica, vol. 95, no. 6, pp. 730-732, 2015.

[12] K. A. Tagg, N. J. Jeoffreys, D. L. Couldwell, J. A. Donald, and G. L. Gilbert, "Fluoroquinolone and macrolide resistance-associated mutations in Mycoplasma genitalium," Journal of Clinical Microbiology, vol. 51, no. 7, pp. 2245-2249, 2013.

[13] M. J. Pond, A. V. Nori, A. A. Witney, R. C. Lopeman, P. D. Butcher, and S. T. Sadiq, "High prevalence of antibiotic-resistant Mycoplasma genitalium in nongonococcal urethritis: the need for routine testing and the inadequacy of current treatment options," Clinical Infectious Diseases, vol. 58, no. 5, pp. 631-637, 2014.

[14] M. Bissessor, S. N. Tabrizi, J. Twin et al., "Macrolide resistance and azithromycin failure in a mycoplasma genitalium-infected cohort and response of azithromycin failures to alternative antibiotic regimens," Clinical Infectious Diseases, vol. 60, no. 8, pp. 1228-1236, 2015.

[15] J. S. Jensen, C. S. Bradshaw, S. N. Tabrizi, C. K. Fairley, and R. Hamasuna, "Azithromycin treatment failure in Mycoplasma genitalium-positive patients with nongonococcal urethritis is associated with induced macrolide resistance," Clinical Infectious Diseases, vol. 47, no. 12, pp. 1546-1553, 2008.

[16] J. Walker, C. K. Fairley, C. S. Bradshaw et al., "Mycoplasma genitalium incidence, organism load, and treatment failure in a cohort of young Australian women," Clinical Infectious Diseases, vol. 56, no. 8, pp. 1094-1100, 2013.

[17] A. Guschin, P. Ryzhikh, T. Rumyantseva, M. Gomberg, and M. Unemo, "Treatment efficacy, treatment failures and selection of macrolide resistance in patients with high load of Mycoplasma genitalium during treatment of male urethritis with josamycin," BMC Infectious Diseases, vol. 15, article 40, 2015.

[18] L. Falk, M. Enger, and J. S. Jensen, "Time to eradication of Mycoplasma genitalium after antibiotic treatment in men and women," Journal of Antimicrobial Chemotherapy, vol. 70, no. 11, pp. 3134-3140, 2015.

[19] L. Ma, J. S. Jensen, M. Mancuso et al., "Genetic variation in the complete $\mathrm{MgPa}$ operon and its repetitive chromosomal elements in clinical strains of Mycoplasma genitalium," PLoS ONE, vol. 5, no. 12, Article ID e15660, 2010.

[20] S. L. Iverson-Cabral, S. G. Astete, C. R. Cohen, E. P. C. Rocha, and P. A. Totten, "Intrastrain heterogeneity of the mgpB gene in Mycoplasma genitalium is extensive in vitro and in vivo and suggests that variation is generated via recombination with repetitive chromosomal sequences," Infection and Immunity, vol. 74, no. 7, pp. 3715-3726, 2006.

[21] P. Oakeshott, A. Aghaizu, P. Hay et al., "Is Mycoplasma genitalium in women the 'New Chlamydia?' A community-based prospective cohort study," Clinical Infectious Diseases, vol. 51, no. 10, pp. 1160-1166, 2010.

[22] J. Vandepitte, H. A. Weiss, N. Kyakuwa et al., "Natural history of Mycoplasma genitalium infection in a cohort of female sex workers in Kampala, Uganda," Sexually Transmitted Diseases, vol. 40, no. 5, pp. 422-427, 2013.

[23] T. Smieszek, P. J. White, and B. A. Wilson, "Apparently-different clearance rates from cohort studies of Mycoplasma genitalium are consistent after accounting for incidence of infection, recurrent infection, and study design," PLOS ONE, vol. 11, no. 2, article e0149087, 2016.

[24] M. J. Parnham, V. E. Haber, E. J. Giamarellos-Bourboulis, G. Perletti, G. M. Verleden, and R. Vos, "Azithromycin: mechanisms of action and their relevance for clinical applications," Pharmacology and Therapeutics, vol. 143, no. 2, pp. 225-245, 2014.

[25] H. S. Yew, T. Anderson, E. Coughlan, and A. Werno, "Induced macrolide resistance in Mycoplasma genitalium isolates from patients with recurrent nongonococcal urethritis," Journal of Clinical Microbiology, vol. 49, no. 4, pp. 1695-1696, 2011.

[26] J. S. Jensen, M. Cusini, and M. Gomberg, 2016 European guideline on Mycoplasma genitalium infections, 2016, http:// iusti.org/regions/Europe/pdf/2016/2016EuropeanMycoplasma Guidelines.pdf.

[27] H. B. Solberg, Hvilket prøvemateriale gir best sensitivitet for deteksjon av mycoplasma genitalium hos kvinner: en studie som ledd $i$ utvikling av retningslinjer for deteksjon av denne bakterien $i$ Norge [Student thesis in Medicine], NTNU, Faculty of Medicine, Department of Cancer Research and Molecular Medicine, Trondheim, Norway, 2015.

[28] J. K. H. Wroblewski, L. E. Manhart, K. A. Dickey, M. K. Hudspeth, and P. A. Totten, "Comparison of transcription-mediated amplification and PCR assay results for various genital specimen types for detection of Mycoplasma genitalium," Journal of Clinical Microbiology, vol. 44, no. 9, pp. 3306-3312, 2006.

[29] R. A. Lillis, M. J. Nsuami, L. Myers, and D. H. Martin, "Utility of urine, vaginal, cervical, and rectal specimens for detection of Mycoplasma genitalium in women," Journal of Clinical Microbiology, vol. 49, no. 5, pp. 1990-1992, 2011.

[30] M. Gosse, H. Lysvand, B. Pukstad, and S. A. Nordbø, "A novel SimpleProbe PCR for detection of mutations in the $23 \mathrm{~S}$ rRNA gene associated with macrolide resistance in Mycoplasma genitalium in clinical samples," Journal of Clinical Microbiology, vol. 54, no. 10, pp. 2563-2567, 2016.

[31] C. Wold, J. Sorthe, U. Hartgill, A. O. Olsen, A. Moghaddam, and N. Reinton, "Identification of macrolide-resistant Mycoplasma genitalium using real-time PCR," Journal of the European 
Academy of Dermatology and Venereology, vol. 29, no. 8, pp. 1616-1620, 2015.

[32] K. Salado-Rasmussen and J. S. Jensen, "Mycoplasma genitalium testing pattern and macrolide resistance: a Danish nationwide retrospective survey," Clinical Infectious Diseases, vol. 59, no. 1, pp. 24-30, 2014.

[33] G. Q. Kristiansen, J. G. Lisby, and K. Schønning, "A 5' nuclease genotyping assay for identification of macrolide-resistant Mycoplasma genitalium in clinical specimens," Journal of Clinical Microbiology, vol. 54, no. 6, pp. 1593-1597, 2016.

[34] R. H. T. Nijhuis, T. T. Severs, D. S. J. M. van der Vegt, A. A. Van Zwet, and J. G. Kusters, "High levels of macrolide resistanceassociated mutations in Mycoplasma genitalium warrant antibiotic susceptibility-guided treatment," Journal of Antimicrobial Chemotherapy, vol. 70, no. 9, pp. 2515-2518, 2015.

[35] C. S. Bradshaw, M. Y. Chen, and C. K. Fairley, "Persistence of Mycoplasma genitalium following azithromycin therapy," PLoS ONE, vol. 3, no. 11, article e3618, 2008.

[36] D. Taylor-Robinson, "Diagnosis and antimicrobial treatment of Mycoplasma genitalium infection: Sobering thoughts," Expert Review of Anti-Infective Therapy, vol. 12, no. 6, pp. 715-722, 2014.

[37] H. Moi, D. F. Vestrheim, and A. O. Olsen, "Reduce the use of one-dose azithromycin," Tidsskrift for den Norske laegeforening, vol. 131, pp. 673-674, 2011. 


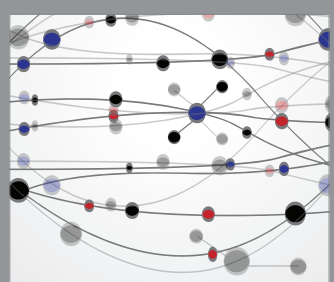

The Scientific World Journal
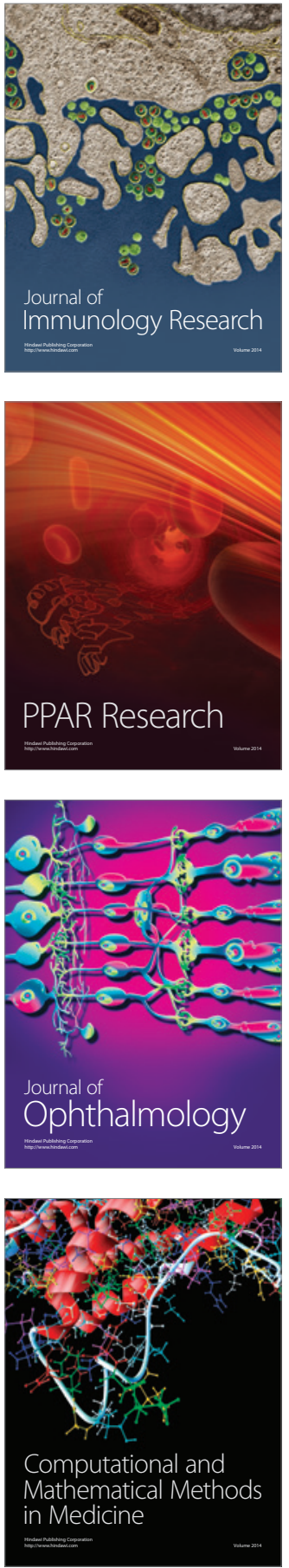

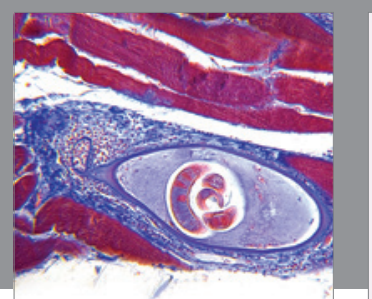

Gastroenterology Research and Practice

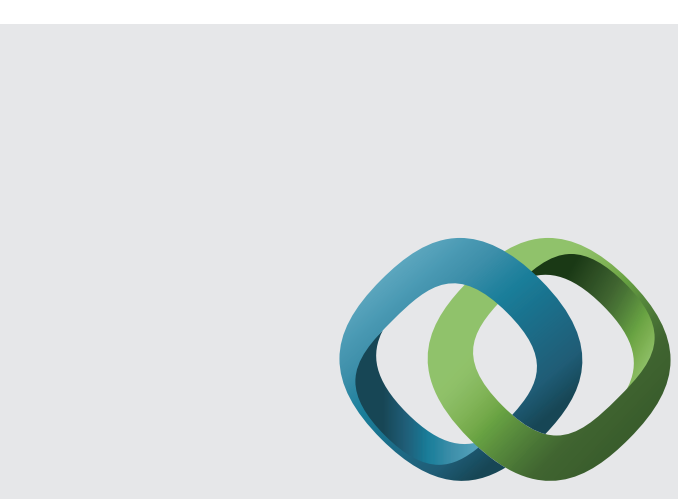

\section{Hindawi}

Submit your manuscripts at

http://www.hindawi.com
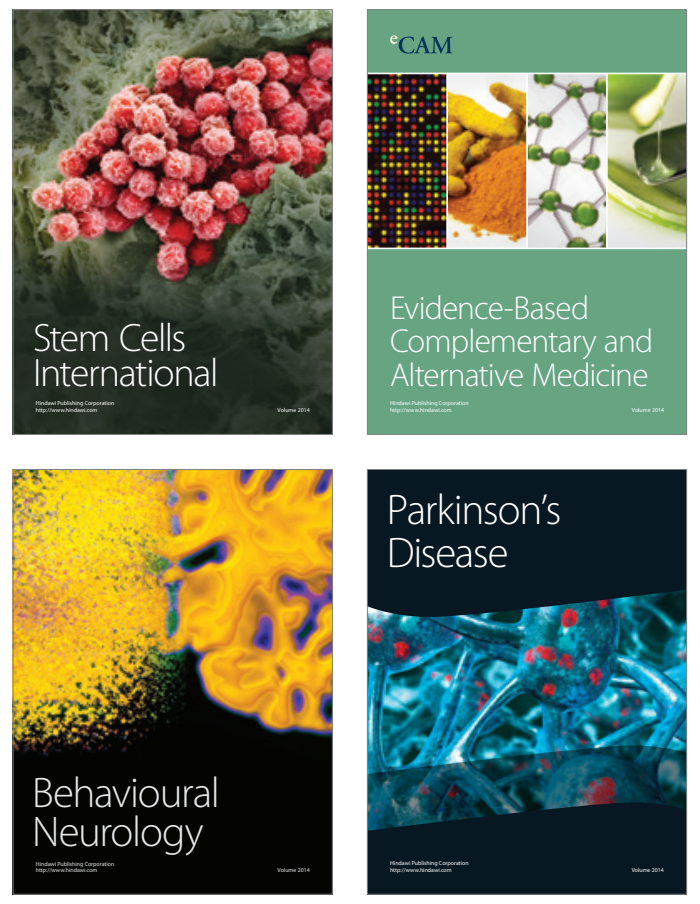
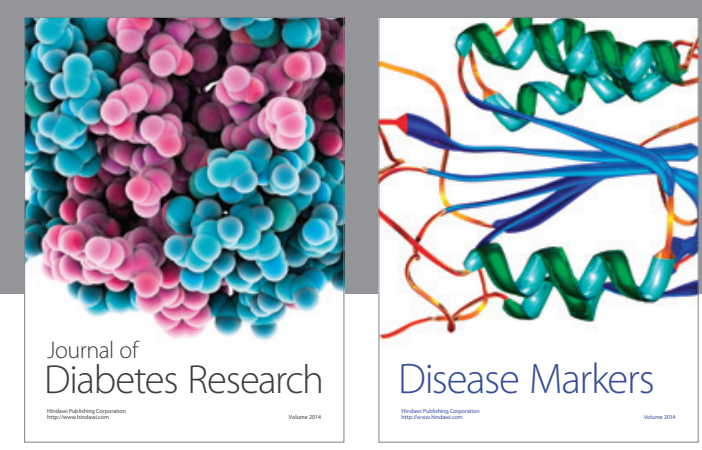

Disease Markers
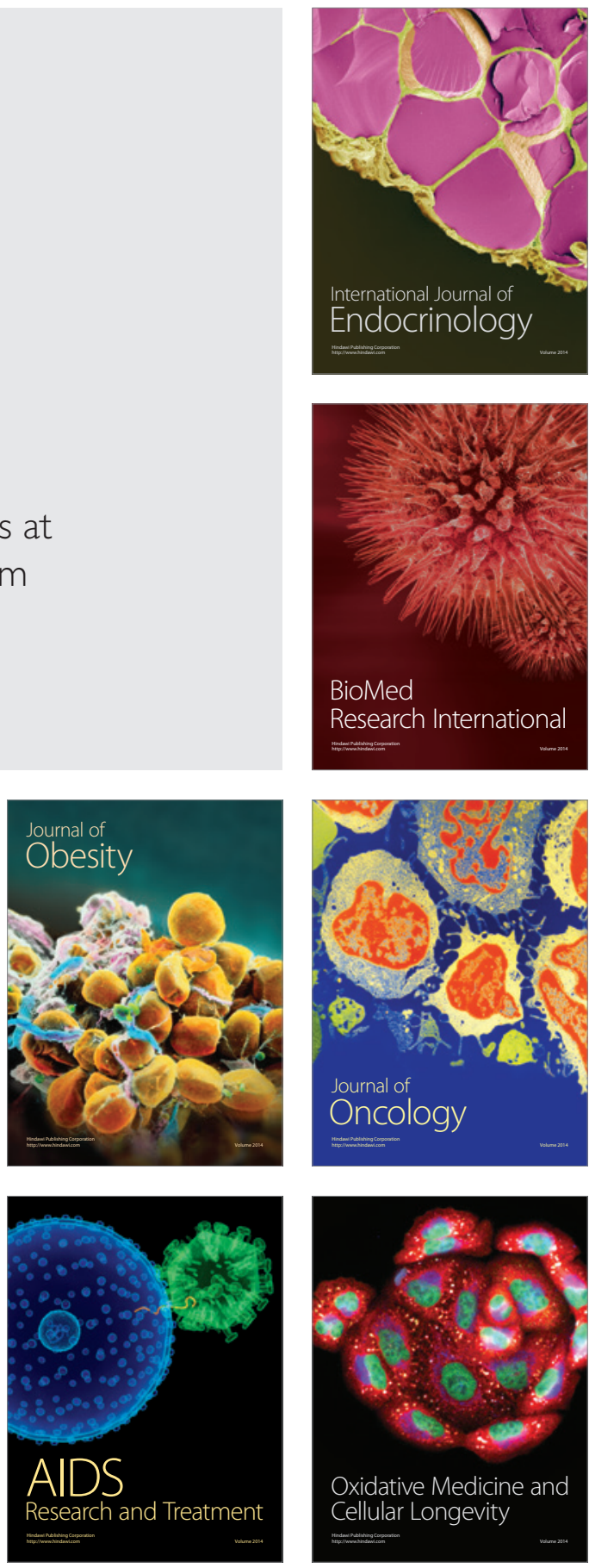